Published in final edited form as:

Neurol Clin. 2012 November ; 30(4): 1299-1312. doi:10.1016/j.ncl.2012.08.008.

\title{
Traumatic Brain Injury and Sleep Disorders
}

\author{
Mari Viola-Saltzman, D.O. and Nathaniel F. Watson, M.D., M.Sc. \\ SYNOPSIS
}

Sleep disturbance is common following traumatic brain injury (TBI), affecting 30-70\% of individuals, many occurring after mild injuries. Insomnia, fatigue and sleepiness are the most frequent post-TBI sleep complaints with narcolepsy (with or without cataplexy), sleep apnea (obstructive and/or central), periodic limb movement disorder, and parasomnias occurring less commonly. In addition, depression, anxiety and pain are common TBI co-morbidities with substantial influence on sleep quality. Two types of TBI negatively impact sleep: contact injuries causing focal brain damage and acceleration/deceleration injuries causing more generalized brain damage. Diagnosis of sleep disorders after TBI may involve polysomnography, multiple sleep latency testing and/or actigraphy. Treatment is disorder specific and may include the use of medications, continuous positive airway pressure (or similar device) and/or behavioral modifications. Unfortunately, treatment of sleep disorders associated with TBI often does not improve sleepiness or neuropsychological function.

\section{Keywords}

Traumatic brain injury; concussion; insomnia; fatigue; hypersomnia; sleep apnea; restless legs syndrome

\section{INTRODUCTION}

Traumatic brain injury (TBI) is a significant cause of disability and death in the United States and worldwide. An estimated 1.6 to 3 million TBIs occur in the United States each year (1) causing over 1 million emergency department visits, 290,000 hospitalizations, and 51,000 deaths.(2) Traumatic brain injury (TBI) is classified as mild, moderate or severe using the Glasgow Coma Scale (mild $=13-15$; moderate $=9-12$; severe $=$ less than or equal to 8 out of 15). TBI can result in significant motor, sensory, cognitive and emotional impairments. Even mild TBI can be associated with headache, dizziness, nausea/vomiting, impaired balance and coordination, vision changes, tinnitus, mood and memory changes, difficulty with memory and attention, and fatigue and/or sleep disturbances.(3) The relationship between head trauma and impaired consciousness and cognitive disturbance

(C) 2012 Elsevier Inc. All rights reserved.

Correspondence: Nathaniel F. Watson, M.D., M.Sc., University of Washington Medicine Sleep Center, 325 Ninth Avenue, Box 359803, Seattle, WA 98104-2499, T: 206-744-4337, F: 206-744-5657, nwatson@uw.edu.

Mari Viola-Saltzman, DO, NorthShore University HealthSystem, 2650 Ridge Ave Evanston, IL 60201, T: 847-570-1678, F:

847-733-5565, mari_viola@hotmail.com

DISCLOSURE

Drs. Viola-Saltzman and Watson have no relevant financial relationships to disclose.

Publisher's Disclaimer: This is a PDF file of an unedited manuscript that has been accepted for publication. As a service to our customers we are providing this early version of the manuscript. The manuscript will undergo copyediting, typesetting, and review of the resulting proof before it is published in its final citable form. Please note that during the production process errors may be discovered which could affect the content, and all legal disclaimers that apply to the journal pertain. 
have been well described,(4) but the association between head injury and sleep disturbance has not been extensively studied. (Table 1)

In the context of sports-related injuries, mild head trauma with an alteration in mental state is referred to as "concussion". The American Academy of Neurology classifies concussion by 3 grades and provides corresponding activity-limiting recommendations. Grade 1 concussion involves confusion that lasts $<15$ minutes absent loss of consciousness (LOC). In this instance, the athlete may return to activity following 15 minutes if they have a normal sideline neurologic exam with rest and exertion. However, in the presence of a previous grade 1 concussion, the athlete should abstain from play for a week. Grade 2 concussion also does not involve LOC, but here the confusion persists for greater than 15 minutes. In this instance, the athlete should not return to play for 1 week and if the athlete has suffered a previous grade 2 concussion, he should refrain from participation for 2 weeks. Any LOC with athletic head injury is a serious grade 3 concussion. If this is the athlete's first high grade concussion then she/he should not participate in athletics for 1 week (if LOC lasted only "seconds"), 2 weeks (if LOC lasted "minutes") or a month (or indefinitely) in the presence of multiple grade 3 concussions.(5) Although it has long been known that repetitive head injuries can lead to "chronic traumatic encephalopathy" or "dementia pugilistica", this topic is receiving ever increasing attention. Recently, congressional hearings focused on the long-term effects of multiple concussions in athletes. The National Football League is paying particular attention to this issue as retired football players, having suffered multiple concussions, later are developing severe cognitive or psychological issues such as dementia and depression.(6) (Table 2)

\section{DIFFERENTIAL DIAGNOSIS (Box 1)}

\section{Box 1}

\section{Differential Diagnosis of Sleep Disturbance following TBI}

Obstructive Sleep Apnea

Central Sleep Apnea

Complex Sleep Apnea

Hypersomnia due to Medical Condition

Circadian Rhythm Sleep Disorder

Insomnia

Parasomnias

Periodic Limb Movement Disorder

Post-traumatic Stress Disorder

Pain

Depression/anxiety

Fatigue

\section{EPIDEMIOLOGY \& RISK FACTORS}

Civilian closed head injuries are typically caused by falls (28\%), motor vehicle accidents (20\%), impact from an object (19\%) and assaults (11\%).(7) These injuries often occur in the context of construction or industrial accidents and domestic and child abuse. There is 
increasing awareness of TBI in military returning from conflicts abroad. Among those deployed, 11-23\% have suffered mild TBI, often from improvised explosive device (IED) blasts.(8) Theodorou and Rice noted that 59\% of blast-exposed veterans of the Afghanistan/ Iraq conflict had TBI.(9)

Sleep disturbances after TBI are estimated to occur in 30-70\% of head injured patients often impairing the resumption of normal activities.(10) The exact prevalence of individual posttraumatic sleep disorders is unknown for a number of reasons. First, the actual occurrence of the causative injury is difficult to ascertain on a population scale, with many milder injuries going unreported. Second, even when reported, there can be substantial variability in gradation of injury along a severity continuum. Lastly, the vast majority of TBI sufferers are never investigated for sleep disorders. Nevertheless, a few studies provide some insight. In a prospective study, Baumann and colleagues found that approximately 3 out of 4 patients who were initially hospitalized for TBI developed sleep-wake disturbances by 6 months after the injury. Most had hypersomnia or fatigue, with insomnia present in only $5 \%$.(11) Other authors have found a higher prevalence of insomnia after TBI.(12) In 200 veterans returning from Operation Enduring Freedom/Operation Iraqi Freedom (OEF/OIF), those with mild TBI and post-traumatic stress disorder (PTSD) had the greater sleep disturbances compared to those without PTSD.(13) In children, 10-38\% with TBI experience sleep disturbances, the highest being in the acute period after the injury.(14-16) (Box 2)

\section{Box 2}

\section{Causes of TBI}

Falls

Motor vehicle accidents

Impact from an object

Assault/violence/abuse

Sports-related injury

Blasts (ie. Improvised Explosive Device)

Firearms

\section{PATHOPHYSIOLOGY}

Head injuries are either penetrating (breaching the calvarium) or closed, in which the calvarium remains intact. The injury may be classified by severity (from mild to severe), mechanism, anatomical features, direction, intensity and/or duration. Closed head injury may be focal (ie. cerebral contusion, epidural hematoma, or intracerebral hemorrhage directly affecting a particular area of brain tissue) or diffuse leading to more widespread axonal injury. Focal injury can result in a coup-contrecoup TBI mechanism where a coup injury occurs under the site of impact with an object, and a contrecoup injury occurs on the side opposite the impacted area. Brain bruising occurs at both sides of the injury. Diffuse injury typically results from acceleration/deceleration or blast waves (e.g., IED blast). Axonal injury results from shearing forces causing microhemorrhages, cerebral edema, increased intracranial pressure and/or changes in cerebral blood flow leading to hypoxia or anoxia. Diffuse damage may have no magnetic resonance imaging (MRI) correlate, although white matter changes can be seen in some cases. (Figures 1, 2, and 3) 
The type of sleep disturbance resulting from a closed head injury depends on the location of injury within sleep-regulating brain regions. Posttraumatic hypersomnia is seen when areas involving the maintenance of wakefulness are damaged. These regions include the brainstem reticular formation, posterior hypothalamus and the area surrounding the third ventricle. High cervical cord lesions have also been known to cause sleepiness and obstructive sleep apnea (OSA).(17) In addition, whiplash may cause hypersomnia by precipitating sleepdisordered breathing.(18)

Low cerebral spinal fluid (CSF) hypocretin-1 levels are found in most cases of narcolepsy with cataplexy, but deficiency of this neuropeptide may not be found in other central hypersomnias.(19) Most patients with moderate-to-severe TBI have low or intermediate hypocretin-1 levels in the acute injury phase.(20) Hypocretin levels tend to normalize (become greater than $200 \mathrm{pg} / \mathrm{mL}$ ) 6 months following the injury, which may explain why post-TBI sleepiness resolves in many over time. $(11,21)$

Coup-contrecoup brain injury following head trauma occurs most frequently at the base of the skull in areas of bony irregularities (especially the sphenoid ridges), with consequent damage to the inferior frontal and anterior temporal regions, including the basal forebrain (an area involved in sleep initiation). As a result, insomnia is a common symptom following injuries of this mechanism. Closed head injury can involve the suprachiasmatic nucleus and/ or its output tracts leading to disturbance of circadian rhythmicity with concomitant hypersomnia and insomnia.

\section{CLINICAL FEATURES \& DIAGNOSIS}

Sleep disturbance is a common complaint following head injury, with milder injuries more likely to disrupt sleep than more severe head trauma.(25-29) Mahmood et al postulate that this may be due to multiple factors such that those with more severe head injuries are less aware of their deficits and may underreport sleep issues. In addition, those with mild TBI may over-endorse sleep complaints or may have greater pressures to reintegrate into their daily life more quickly leading to increased stress and sleep issues. Lastly, neurobiological differences between mild and severe injuries may lead to more sleep complaints in mild TBI.(25) A common pattern following TBI includes difficulties initiating and maintaining sleep, with or without concomitant daytime sleepiness. A large epidemiological study showed that up to half of those suffering TBI endorsed insomnia symptoms of some type. (30) Causation can be due to diverse clinical and other factors such as: pain, injury to sleep/ wake regulatory nuclei and pathways in the brain (e.g., ventrolateral preoptic nucleus or its projections), post-traumatic stress disorder, maladaptive behaviors or other factors preventing the occurrence of sleep.

In some cases, the post-TBI insomnia is a manifestation of a circadian rhythm sleep disorder, typically delayed sleep phase or irregular sleep-wake type.(31) In delayed sleep phase, the subject is delayed in relation to naturally occurring light/dark cycles, resulting in early morning bedtimes and late morning/afternoon wake times. When the TBI patient with this circadian pattern attempts to conform to traditional bedtime/wake times they struggle with sleep onset insomnia having gone to bed long before their internal biological clock would have preferred. In irregular sleep/wake circadian type, the TBI patient has multiple irregular sleep/wake bouts throughout the day and night with seemingly no link to traditional light/dark cycles. The only thing normal about their sleep is the amount they get per 24hours.

Objective testing with polysomnography (PSG) and multiple sleep latency testing (MSLT) can be helpful in the workup of these patients. Patients with mild TBI (27.9 months postinjury; $\mathrm{SD}=15.5$ months) undergoing PSG were found to have less efficient sleep and longer 
sleep-onset latencies compared to controls.(32) Nightmares commonly interrupt sleep in veterans with PTSD and mild TBI.(33) Veterans of the United States campaigns in Afghanistan (Operation Enduring Freedom [OEF]) and Iraq (Operation Iraqi Freedom [OIF]) complaining of insomnia associated with mild TBI and PSTD were subjectively sleepier compared to veterans with insomnia due to PTSD alone.(34)

Hypersomnia with or without involuntary sleep attacks may also develop after a head injury, so called "secondary narcolepsy" or "posttraumatic hypersomnia." If hypersomnia persists for 3 months after a head injury (with or without cataplexy) with a mean sleep onset latency (SOL) of less than 8 minutes and 2 or more sleep-onset rapid eye movement periods (SOREMPs) are found on MSLT, the diagnosis is "narcolepsy due to medical condition." If 3 months of hypersomnia persists after a head injury and MSLT shows a mean SOL of less than 8 minutes with less than 2 SOREMPS, then the diagnosis is "hypersomnia due to medical condition" (posttraumatic hypersomnia).(35) Overnight sleep may or may not be prolonged compared to the pre-trauma period. Ancillary symptoms attributed to daytime somnolence may also occur, such as difficulty with concentration, memory impairment and fatigue.

A number of other sleep disorders have also been found in patients with head trauma. Masel and colleagues examined a series of 71 brain injury patients in a residential treatment program, all without a prior history of hypersomnia or sleep disturbances. Among the 33 (46.5\%) hypersomnolent patients, 4 had OSA, 7 had periodic limb movement disorder (PLMD) and 1 had narcolepsy (in addition to periodic limb movement disorder). The remaining 21 hypersomnolent patients were given a diagnosis of "posttraumatic hypersomnia".(36) In an extensive series of 184 TBI patients, Guilleminault and colleagues found that the majority of patients admitted to objective sleepiness and only $17 \%$ of the patients had a normal mean SOL (greater than 10 minutes) on MSLT. Thirty-two percent of the patients were found to suffer from sleep-disordered breathing (primarily OSA). The authors noted that all 16 whiplash patients were diagnosed with sleep-disordered breathing indicating the importance of considering the mechanism of the injury when evaluating the TBI patient with a sleep complaint. Pain was also found to be a significant cause of nocturnal sleep disruption and daytime impairment.(18) Castriotta and colleagues prospectively studied 87 adults at least 3 months after TBI. PSG and MSLT were administered to all subjects; $46 \%$ had abnormal sleep studies. The authors diagnosed $23 \%$ with OSA, $11 \%$ with posttraumatic hypersomnia, $7 \%$ with periodic limb movements in sleep and $6 \%$ with narcolepsy.(37) Head trauma has been reported to precipitate a few cases of Kleine-Levin syndrome, a rare disorder consisting of recurrent hypersomnia and cognitive or behavioral disturbances, hypersexuality and compulsive eating.(38)

Head trauma occasionally triggers parasomnias, including sleepwalking, sleep terrors, REM sleep behavior disorder (abnormal dream-enacting behavior during a normally atonic state) and dissociative disorders.(39) These studies indicate that TBI can precipitate almost every sleep disorder, which emphasizes the importance of careful history taking and physical examination when diagnosing sleep disturbance in this patient population.

Fatigue is another complaint associated with TBI with untoward consequences for quality of life. In a study of 119 patients at least 1 year after TBI, up to 53\% reported fatigue, which was more prevalent in women or those with symptoms of depression, pain or sleep disturbances.(40) In another study of individuals with moderate-to-severe TBI, 16\%-32\% and $21 \%-34 \%$ (at years 1 and 2 respectively) reported significant levels of fatigue.(41) Fatigue and sleepiness can be difficult to disentangle by even the most experienced clinician highlighting the importance of objective assessments of sleepiness such as the MSLT and 
the ability to stay awake such as the maintenance of wakefulness test (MWT) in these patients.

Depression and anxiety are common after TBI. Patients with mild TBI and sleep complaints reported feeling depressed at 10 days and 6 weeks after their injury.(42) New onset anxiety after head injury is a significant predictor of sleep disturbance, though the cause-effect relationship is unclear.(43) In addition, pain is a common comorbid condition, contributing to sleep disturbances and also associated with mood issues.

The relationship between sleep disturbance and TBI in children is less well characterized than in adults. Common risk factors for disturbed sleep in children following TBI include mild injury, psychosocial problems (defined by the Pediatric Symptoms Checklist [PSC-17], a one page questionnaire completed by the parent to assess emotional and behavioral problems in the child) and pain. Children with TBI suffer from a higher severity and more prolonged duration of sleep disturbances compared to children with orthopedic injury. Sleep disturbances are significant predictors of poorer functional outcomes in children with moderate or severe TBI.(44) Other studies in children indicate that mild TBI increases nocturnal waking and reduces sleep efficiency.(45) These sleep disturbances may contribute to psychological, social and academic difficulties.

\section{TREATMENT}

Post-TBI insomnia is often refractory to conventional treatments. Patients are commonly treated with benzodiazepines, especially in patients with underlying anxiety. The nonbenzodiazepine benzodiazepine receptor agonists zolpidem, zaleplon and eszopiclone have been extensively used in this population with moderate success. Cognitive behavioral therapy for insomnia (CBTi) including: stimulus control, sleep restriction, cognitive restructuring, sleep hygiene education, and fatigue management can improve nocturnal sleep quality as well as reduce daytime fatigue.(46) In veterans suffering from PTSD and chronic sleep disturbances (TBI not defined), prazosin and CBT were both found to be effective (compared to placebo) in improving sleep continuity and nightmare frequency.(47) Accupuncture may also be a viable treatment in improving sleep quality following TBI.(48)

Patients with narcolepsy or hypersomnia secondary to a head injury may require stimulant medications such as modafinil, methylphenidate, or amphetamines in doses similar to those used for idiopathic narcolepsy. A prospective, double-blind, randomized, placebo-controlled trial found that modafinil (100 to $200 \mathrm{mg}$ given each morning) significantly improved sleepiness in those with TBI as measured by the Epworth Sleepiness Scale (ESS) and the MWT. However, modafinil was not found to be effective for fatigue in these individuals. (49) In contrast, another study found modafinil to be of limited effectiveness for sleepiness associated with TBI.(50) Clinicians should note that more conservative treatments, such as strategic naps and caffeine use are quite helpful for those with post-TBI hypersomnolence.

Cases of sleep apnea resulting from head injury are treated with CPAP or bilevel positive airway pressure (BiPAP) with or without a backup rate. Sometimes ASV is necessary for central sleep apnea or complex sleep apnea (a combination of obstructive and central events). Other treatments for OSA may include mandibular advancement devices, surgical approaches to the proximal airway and conservative treatments like weight loss and body positioning during sleep. Mandibular advancement devices are constructed by a dentist (ideally one with a specialization in sleep medicine) and reposition the lower jaw forward in an effort to reduce obstructions in the airway by pulling the tongue away from the posterior pharyngeal wall and tightening up the palate. Surgical approaches are diverse and typically tailored to the individual patient, with common procedures including uvulopalatopharyngopasty, tonsillectomy and genioglossus advancement. (Flowchart 1) 
Periodic limb movement disorder related to TBI is typically treated with dopamine agonist medications (i.e., ropinirole or pramipexole). Importantly, iron storage levels should be investigated in these patients to ensure a ferritin $>50$. Iron is a co-factor for tyrosine hydroxylase in the production of dopamine in the pre-synaptic bouton, with low levels thought to compromise dopamine synthesis and precipitate restless legs syndrome (RLS) and PLMD. In the event of low ferritin, iron supplementation is the treatment of choice.

Parasomnias are often treated with behavioral approaches (ie. relaxation techniques, mental imagery and/or anticipatory awakenings) and medications such as benzodiazepines and tricyclic antidepressants. It is pertinent to rule out another sleep disorder (especially OSA) as the cause of the parasomnia. Medications, alcohol use, stress and/or illness may contribute to or cause parasomnia symptoms. In those with sleep walking behaviors it is pertinent to ensure a safe sleeping environment by locking doors and windows, moving obstacles and sleeping on the ground floor. A low dose of clonazepam or melatonin may be used to treat RBD. Lastly, prazosin is often utilized in veterans with PTSD to treat nightmares.

When approaching the patient with post-TBI sleep disorders, the clinician must also attend to underlying pain, depression, and anxiety as these issues can greatly impact sleep. However, avoidance (or minimization) of narcotic medications for pain is prudent if possible since these medications can worsen TBI-related sleep apnea. Tricyclic antidepressants are frequently used to treat chronic pain issues and may also be helpful with insomnia due to their sedating effects. Benzodiazepines used for anxiety or sedation may also worsen sleep apnea and are associated with worse cognitive outcomes. Those "self-medicating" post-TBI symptoms with alcohol risk sleep disruption, nightmares, reduction in REM sleep, and worsening sleep apnea. Selective serotonin reuptake inhibitors (SSRIs) for depression or anxiety should be taken in the morning since they can induce insomnia when taken at bedtime. Lastly, sedating antidepressants, such as trazodone and mirtazapine are helpful to treat insomnia, regardless of the presence or absence of comorbid mood issues. (Flowchart 2)

\section{PROGNOSIS}

There are few follow-up studies regarding posttraumatic sleep disorders and therefore the natural history of these disorders is not well known. In general, sleep disruption in TBI may impair rehabilitation participation and delay recovery due to its negative impact on psychological functioning (i.e. depression and anxiety) and pain perception. Once stabilized, sleep disturbances related to TBI show little further change, other than an improvement with treatment. A prospective cohort study examined sleepiness in 514 TBI patients 1 month after the injury and again at 1 year. At 1 month, 55\% endorsed at least 1 item on a 4 -item sleepiness questionnaire. Injury severity was associated with sleepiness endorsement, with the more severely injured indicating greater sleepiness. One year later, although $27 \%$ continued to endorse sleepiness on at least 1 of 4 items, the vast majority of subjects had some level of improvement in their sleepiness. This study suggests that, although symptoms persist in many, some TBI patients can expect their sleepiness to improve or resolve over time.(21) Another prospective study of 51 TBI patients showed that at 3 years post-injury, $67 \%$ of the patients continued to complain of sleep-wake disturbances, especially fatigue and hypersomnia.(51) In a study of 31 closed head injury patients admitted to a TBI rehabilitation unit, nurses maintained patient sleep logs and disturbed nocturnal sleep was felt to be a marker of more severe injury since these patients had longer stays in the acute trauma center and rehabilitation unit.(52) Lastly, a study of 14 patients in a TBI rehabilitation unit wearing actigraphy, and monitored daily by speech and language therapists using the Orientation Log (O-LOG) for assessment of posttraumatic anmnesia, revealed improved sleep efficiency with resolution of posttraumatic amnesia.(53) 
In persons with TBI, the presence of OSA is associated with greater impairment of sustained attention and memory than in patients with comparable severity TBI without OSA.(54) TBI patients with excessive daytime sleepiness have slower reaction times and poorer performance on the Psychomotor Vigilance Test than non-sleepy patients.(37)

Unfortunately, treatment of sleep disorders associated with TBI often does not improve sleepiness or neuropsychological function. In an unselected group of 57 patients with TBI, Castriotta and colleagues documented sleep disorders in 22 subjects (39\%) by PSG. Treatment did not lead to significant changes in quality of life, mood or cognitive performance. Treatment of OSA (13 subjects, 23\%) with CPAP did not lead to improvement in sleepiness, as measured by the ESS and MSLT.(55) (See case report in box 3 and current controversies in box 4.)

\section{Box 3}

\section{Case Presentation}

A 42 year-old man suffered closed head and whiplash injuries following a motor vehicle accident. About 1 month after the event he developed symptoms of sleep apnea, including snoring, sleepiness and witnessed apneas. He denied experiencing these symptoms prior to the injury. Examination was remarkable for a body mass index of 27, neck circumference of 17 inches, and normal oropharyngeal anatomy.

Polysomnography showed an apnea hypopnea index (AHI) of 65, consisting mainly of obstructive apneas and hypopneas, but also included a moderate number of central and mixed apneas. He was given a diagnosis of "severe sleep apnea, predominantly obstructive but with a central component." He underwent a continuous positive airway pressure (CPAP) titration study and then initiated CPAP therapy. This improved his sleepiness, but he continued to have frequent nocturnal awakenings despite use of eszopiclone. His CPAP download showed persistence of central apneas. He the returned to the laboratory for an adaptive-servo ventilation (ASV) titration study and reported improved hypersomnia after implementation of this treatment modality.

\section{BOX 4}

\section{CURRENT CONTROVERSIES AND FUTURE CONSIDERATIONS}

1. The role of potential neuroprotection or immunomodulation (i.e. steroids, other) following TBI and the effect on subsequent development of sleep disorders.

2. The timing of assessment of sleep in post-TBI patients, should it be in the acute setting or later? Does intervening sooner improve rehabilitation participation and improve long-term outcomes?

3. What is the neuroanatomical substrate of narcolepsy due to medical condition in patients with post-TBI sleepiness? Is there a role for serial CSF hypocretin-1 measurement to assess prognosis in these patients?

4. What is the mechanism for post-TBI OSA? Is whiplash injury the primary mechanism or are there other neuroanatomical causes? 


\section{SUGGESTED READINGS AND REFERENCES}

1. Nonfatal traumatic brain injuries from sports and recreation activities--United States, 2001-2005. MMWR Morbidity and mortality weekly report. 2007; 56(29):733-7. Epub 2007/07/28. [PubMed: 17657206]

2. Rutland-Brown W, Langlois JA, Thomas KE, Xi YL. Incidence of traumatic brain injury in the United States, 2003. The Journal of head trauma rehabilitation. 2006; 21(6):544-8. Epub 2006/11/24. [PubMed: 17122685]

3. Winston SR. Preliminary communication: EMT and the Glasgow [correction of Glascow] Coma Scale. Journal of the Iowa Medical Society. 1979; 69(10):393, 8. Epub 1979/10/01. [PubMed: 490000]

4. Bricolo A, Gentilomo A, Rosadini G, Rossi GF. Long-lasting post-traumatic unconsciousness. A study based on nocturnal EEG and polygraphic recording. Acta neurologica Scandinavica. 1968; 44(4):513-32. Epub 1968/01/01. [PubMed: 5687886]

5. Practice parameter: the management of concussion in sports (summary statement). Report of the Quality Standards Subcommittee. Neurology. 1997; 48(3):581-5. Epub 1997/03/01. [PubMed: 9065530]

6. DeKosky ST, Ikonomovic MD, Gandy S. Traumatic brain injury--football, warfare, and long-term effects. The New England journal of medicine. 2010; 363(14):1293-6. Epub 2010/10/01. [PubMed: 20879875]

7. Langlois JA, Rutland-Brown W, Wald MM. The epidemiology and impact of traumatic brain injury: a brief overview. The Journal of head trauma rehabilitation. 2006; 21(5):375-8. Epub 2006/09/20. [PubMed: 16983222]

8. Schultz BA, Cifu DX, McNamee S, Nichols M, Carne W. Assessment and treatment of common persistent sequelae following blast induced mild traumatic brain injury. NeuroRehabilitation. 2011; 28(4):309-20. Epub 2011/07/05. [PubMed: 21725164]

9. Theodorou AARS. Is the silent epidemic keeping patients awake? Journal of clinical sleep medicine: JCSM: official publication of the American Academy of Sleep Medicine. 2007; 3(4):347-8. [PubMed: 17694721]

10. Ouellet MC, Savard J, Morin CM. Insomnia following traumatic brain injury: a review. Neurorehabil Neural Repair. 2004; 18(4):187-98. Epub 2005/01/26. [PubMed: 15669131]

11. Baumann CR, Werth E, Stocker R, Ludwig S, Bassetti CL. Sleep-wake disturbances 6 months after traumatic brain injury: a prospective study. Brain: a journal of neurology. 2007; 130(Pt 7):187383. Epub 2007/06/23. [PubMed: 17584779]

12. Verma A, Anand V, Verma NP. Sleep disorders in chronic traumatic brain injury. Journal of clinical sleep medicine: JCSM: official publication of the American Academy of Sleep Medicine. 2007; 3(4):357-62. Epub 2007/08/19. [PubMed: 17694723]

13. Lew HL, Pogoda TK, Hsu PT, Cohen S, Amick MM, Baker E, et al. Impact of the "polytrauma clinical triad" on sleep disturbance in a department of veterans affairs outpatient rehabilitation setting. American journal of physical medicine \& rehabilitation/Association of Academic Physiatrists. 2010; 89(6):437-45. Epub 2010/05/22.

14. Blinman TA, Houseknecht E, Snyder C, Wiebe DJ, Nance ML. Postconcussive symptoms in hospitalized pediatric patients after mild traumatic brain injury. Journal of pediatric surgery. 2009; 44(6):1223-8. Epub 2009/06/16. [PubMed: 19524745]

15. Hawley CA, Ward AB, Magnay AR, Long J. Children's brain injury: a postal follow-up of 525 children from one health region in the UK. Brain injury: [BI]. 2002; 16(11):969-85. Epub 2002/11/22.

16. Kraus J, Hsu P, Schaffer K, Vaca F, Ayers K, Kennedy F, et al. Preinjury factors and 3-month outcomes following emergency department diagnosis of mild traumatic brain injury. The Journal of head trauma rehabilitation. 2009; 24(5):344-54. Epub 2009/10/28. [PubMed: 19858968]

17. Leduc BE, Dagher JH, Mayer P, Bellemare F, Lepage Y. Estimated prevalence of obstructive sleep apnea-hypopnea syndrome after cervical cord injury. Archives of physical medicine and rehabilitation. 2007; 88(3):333-7. Epub 2007/02/27. [PubMed: 17321826] 
18. Guilleminault C, Yuen KM, Gulevich MG, Karadeniz D, Leger D, Philip P. Hypersomnia after head-neck trauma: a medicolegal dilemma. Neurology. 2000; 54(3):653-9. Epub 2000/02/19. [PubMed: 10680799]

19. Dauvilliers Y, Baumann CR, Carlander B, Bischof M, Blatter T, Lecendreux M, et al. CSF hypocretin-1 levels in narcolepsy, Kleine-Levin syndrome, and other hypersomnias and neurological conditions. J Neurol Neurosurg Psychiatry. 2003; 74(12):1667-73. Epub 2003/11/26. [PubMed: 14638887]

20. Baumann CR, Stocker R, Imhof HG, Trentz O, Hersberger M, Mignot E, et al. Hypocretin-1 (orexin A) deficiency in acute traumatic brain injury. Neurology. 2005; 65(1):147-9. Epub 2005/07/13. [PubMed: 16009905]

21. Watson NF, Dikmen S, Machamer J, Doherty M, Temkin N. Hypersomnia following traumatic brain injury. Journal of clinical sleep medicine: JCSM: official publication of the American Academy of Sleep Medicine. 2007; 3(4):363-8. Epub 2007/08/19. [PubMed: 17694724]

22. Carter KA, Lettieri CJ, Pena JM. An unusual cause of insomnia following IED-induced traumatic brain injury. Journal of clinical sleep medicine: JCSM: official publication of the American Academy of Sleep Medicine. 2010; 6(2):205-6. Epub 2010/04/24. [PubMed: 20411701]

23. Shekleton JA, Parcell DL, Redman JR, Phipps-Nelson J, Ponsford JL, Rajaratnam SM. Sleep disturbance and melatonin levels following traumatic brain injury. Neurology. 2010; 74(21):17328. Epub 2010/05/26. [PubMed: 20498441]

24. Llompart-Pou JA, Perez G, Raurich JM, Riesco M, Brell M, Ibanez J, et al. Loss of cortisol circadian rhythm in patients with traumatic brain injury: a microdialysis evaluation. Neurocrit Care. 2010; 13(2):211-6. Epub 2010/07/02. [PubMed: 20593248]

25. Mahmood O, Rapport LJ, Hanks RA, Fichtenberg NL. Neuropsychological performance and sleep disturbance following traumatic brain injury. The Journal of head trauma rehabilitation. 2004; 19(5):378-90. Epub 2004/12/15. [PubMed: 15597029]

26. Pillar G, Averbooch E, Katz N, Peled N, Kaufman Y, Shahar E. Prevalence and risk of sleep disturbances in adolescents after minor head injury. Pediatric neurology. 2003; 29(2):131-5. Epub 2003/10/29. [PubMed: 14580656]

27. Clinchot DM, Bogner J, Mysiw WJ, Fugate L, Corrigan J. Defining sleep disturbance after brain injury. American journal of physical medicine \& rehabilitation/Association of Academic Physiatrists. 1998; 77(4):291-5. Epub 1998/08/26.

28. Beetar JT, Guilmette TJ, Sparadeo FR. Sleep and pain complaints in symptomatic traumatic brain injury and neurologic populations. Archives of physical medicine and rehabilitation. 1996; 77(12): 1298-302. Epub 1996/12/01. [PubMed: 8976315]

29. Fichtenberg NL, Millis SR, Mann NR, Zafonte RD, Millard AE. Factors associated with insomnia among post-acute traumatic brain injury survivors. Brain injury: [BI]. 2000; 14(7):659-67. Epub 2000/07/29.

30. Ouellet MC, Morin CM. Subjective and objective measures of insomnia in the context of traumatic brain injury: a preliminary study. Sleep medicine. 2006; 7(6):486-97. Epub 2006/08/29. [PubMed: 16934524]

31. Ayalon L, Borodkin K, Dishon L, Kanety H, Dagan Y. Circadian rhythm sleep disorders following mild traumatic brain injury. Neurology. 2007; 68(14):1136-40. Epub 2007/04/04. [PubMed: 17404196]

32. Williams BR, Lazic SE, Ogilvie RD. Polysomnographic and quantitative EEG analysis of subjects with long-term insomnia complaints associated with mild traumatic brain injury. Clin Neurophysiol. 2008; 119(2):429-38. Epub 2007/12/18. [PubMed: 18083618]

33. Ruff RL, Ruff SS, Wang XF. Improving sleep: initial headache treatment in OIF/OEF veterans with blast-induced mild traumatic brain injury. Journal of rehabilitation research and development. 2009; 46(9):1071-84. Epub 2009/01/01. [PubMed: 20437313]

34. Wallace DM, Shafazand S, Ramos AR, Carvalho DZ, Gardener H, Lorenzo D, et al. Insomnia characteristics and clinical correlates in Operation Enduring Freedom/Operation Iraqi Freedom veterans with post-traumatic stress disorder and mild traumatic brain injury: an exploratory study. Sleep medicine. 2011; 12(9):850-9. Epub 2011/09/20. [PubMed: 21925943] 
35. American Academy of Sleep Medicine. The international classification of sleep disorders: diagnostic and coding manual. 2. Vol. xviii. Westchester, Ill: American Academy of Sleep Medicine; 2005. p. 297

36. Masel BE, Scheibel RS, Kimbark T, Kuna ST. Excessive daytime sleepiness in adults with brain injuries. Archives of physical medicine and rehabilitation. 2001; 82(11):1526-32. Epub 2001/11/02. [PubMed: 11689971]

37. Castriotta RJ, Wilde MC, Lai JM, Atanasov S, Masel BE, Kuna ST. Prevalence and consequences of sleep disorders in traumatic brain injury. Journal of clinical sleep medicine: JCSM: official publication of the American Academy of Sleep Medicine. 2007; 3(4):349-56. Epub 2007/08/19. [PubMed: 17694722]

38. Arnulf I, Zeitzer JM, File J, Farber N, Mignot E. Kleine-Levin syndrome: a systematic review of 186 cases in the literature. Brain: a journal of neurology. 2005; 128(Pt 12):2763-76. Epub 2005/10/19. [PubMed: 16230322]

39. Schenck CH, Boyd JL, Mahowald MW. A parasomnia overlap disorder involving sleepwalking, sleep terrors, and REM sleep behavior disorder in 33 polysomnographically confirmed cases. Sleep. 1997; 20(11):972-81. Epub 1998/02/11. [PubMed: 9456462]

40. Englander J, Bushnik T, Oggins J, Katznelson L. Fatigue after traumatic brain injury: Association with neuroendocrine, sleep, depression and other factors. Brain injury: [BI]. 2010; 24(12):137988. Epub 2010/10/22.

41. Bushnik T, Englander J, Wright J. Patterns of fatigue and its correlates over the first 2 years after traumatic brain injury. The Journal of head trauma rehabilitation. 2008; 23(1):25-32. Epub 2008/01/26. [PubMed: 18219232]

42. Chaput G, Giguere JF, Chauny JM, Denis R, Lavigne G. Relationship among subjective sleep complaints, headaches, and mood alterations following a mild traumatic brain injury. Sleep medicine. 2009; 10(7):713-6. Epub 2009/01/17. [PubMed: 19147402]

43. Rao V, Spiro J, Vaishnavi S, Rastogi P, Mielke M, Noll K, et al. Prevalence and types of sleep disturbances acutely after traumatic brain injury. Brain injury: [BI]. 2008; 22(5):381-6. Epub 2008/04/17.

44. Tham SW, Palermo TM, Vavilala MS, Wang J, Jaffe KM, Koepsell TD, et al. The longitudinal course, risk factors, and impact of sleep disturbances in children with traumatic brain injury. $\mathrm{J}$ Neurotrauma. 2012; 29(1):154-61. Epub 2011/10/28. [PubMed: 22029569]

45. Kaufman Y, Tzischinsky O, Epstein R, Etzioni A, Lavie P, Pillar G. Long-term sleep disturbances in adolescents after minor head injury. Pediatric neurology. 2001; 24(2):129-34. Epub 2001/03/29. [PubMed: 11275462]

46. Ouellet MC, Morin CM. Efficacy of cognitive-behavioral therapy for insomnia associated with traumatic brain injury: a single-case experimental design. Archives of physical medicine and rehabilitation. 2007; 88(12):1581-92. Epub 2007/12/01. [PubMed: 18047872]

47. Germain A, Richardson R, Moul DE, Mammen O, Haas G, Forman SD, et al. Placebo-controlled comparison of prazosin and cognitive-behavioral treatments for sleep disturbances in US Military Veterans. Journal of psychosomatic research. 2012; 72(2):89-96. Epub 2012/01/28. [PubMed: 22281448]

48. Zollman FS, Larson EB, Wasek-Throm LK, Cyborski CM, Bode RK. Acupuncture for Treatment of Insomnia in Patients With Traumatic Brain Injury: A Pilot Intervention Study. The Journal of head trauma rehabilitation. 2011 Epub 2011/03/10.

49. Kaiser PR, Valko PO, Werth E, Thomann J, Meier J, Stocker R, et al. Modafinil ameliorates excessive daytime sleepiness after traumatic brain injury. Neurology. 2010; 75(20):1780-5. Epub 2010/11/17. [PubMed: 21079179]

50. Jha A, Weintraub A, Allshouse A, Morey C, Cusick C, Kittelson J, et al. A randomized trial of modafinil for the treatment of fatigue and excessive daytime sleepiness in individuals with chronic traumatic brain injury. The Journal of head trauma rehabilitation. 2008; 23(1):52-63. Epub 2008/01/26. [PubMed: 18219235]

51. Kempf J, Werth E, Kaiser PR, Bassetti CL, Baumann CR. Sleep-wake disturbances 3 years after traumatic brain injury. J Neurol Neurosurg Psychiatry. 2010; 81(12):1402-5. Epub 2010/10/05. [PubMed: 20884672] 
52. Makley MJ, English JB, Drubach DA, Kreuz AJ, Celnik PA, Tarwater PM. Prevalence of sleep disturbance in closed head injury patients in a rehabilitation unit. Neurorehabil Neural Repair. 2008; 22(4):341-7. Epub 2008/07/30. [PubMed: 18663247]

53. Makley MJ, Johnson-Greene L, Tarwater PM, Kreuz AJ, Spiro J, Rao V, et al. Return of memory and sleep efficiency following moderate to severe closed head injury. Neurorehabil Neural Repair. 2009; 23(4):320-6. Epub 2009/01/28. [PubMed: 19171947]

54. Wilde MC, Castriotta RJ, Lai JM, Atanasov S, Masel BE, Kuna ST. Cognitive impairment in patients with traumatic brain injury and obstructive sleep apnea. Archives of physical medicine and rehabilitation. 2007; 88(10):1284-8. Epub 2007/10/03. [PubMed: 17908570]

55. Castriotta RJ, Atanasov S, Wilde MC, Masel BE, Lai JM, Kuna ST. Treatment of sleep disorders after traumatic brain injury. Journal of clinical sleep medicine: JCSM: official publication of the American Academy of Sleep Medicine. 2009; 5(2):137-44. Epub 2009/12/09. [PubMed: 19968047] 


\section{KEY POINTS}

- Sleep disturbances occur in 30-70\% of individuals with traumatic brain injury (TBI).

- Insomnia, fatigue and sleepiness are the most frequent complaints after head injury.

- The 2 main types of traumatic brain injuries leading to altered sleep involve contact and acceleration/deceleration injuries.

- Diagnosis of sleep disorder(s) after traumatic brain injury may include polysomnography, multiple sleep latency testing and/or actigraphy.

- Treatment is disorder-specific and may include the use of medications, continuous positive airway pressure (or similar device) and/or behavioral modifications. 

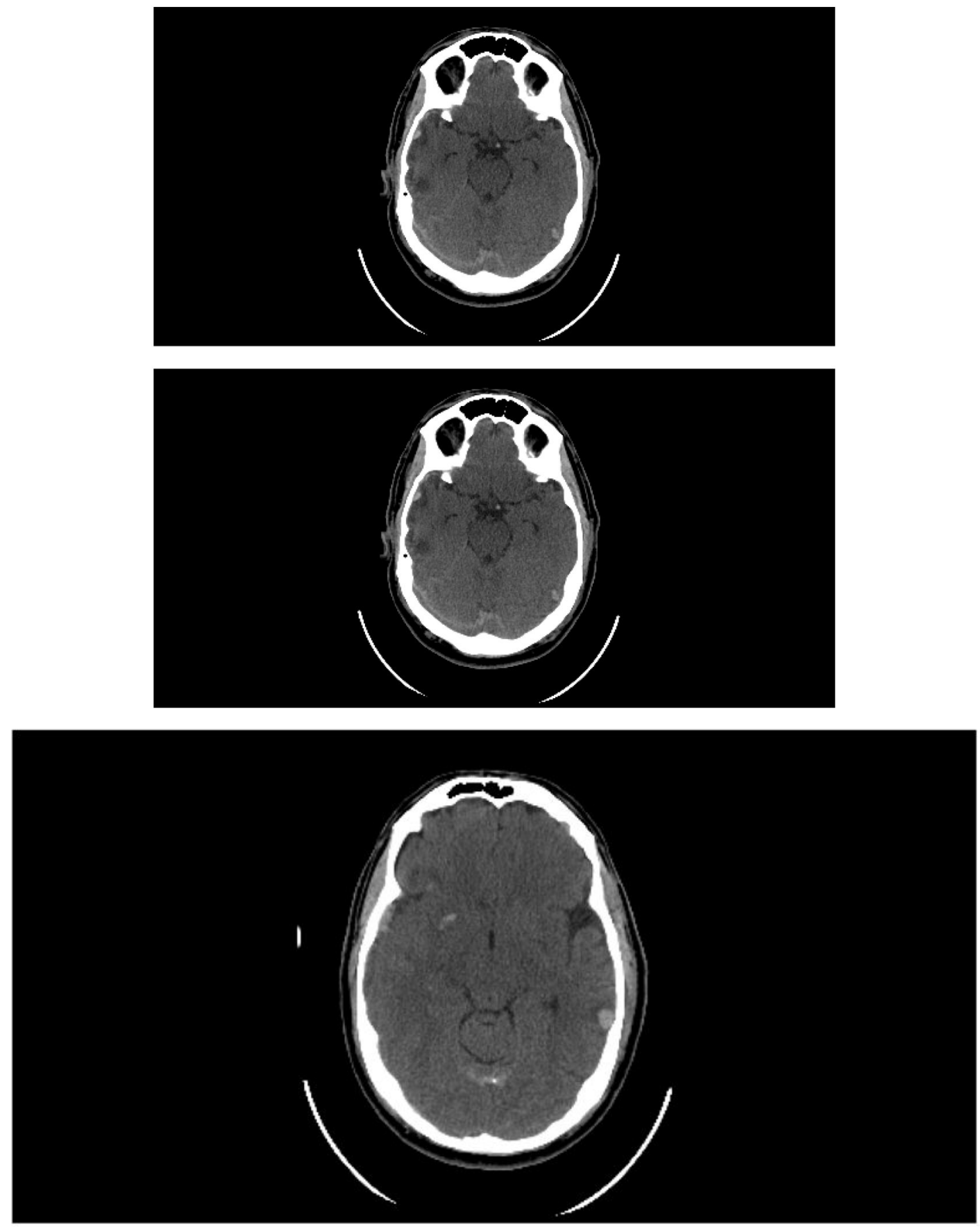

Figure 1.

Coup-contrecoup injury following right temporal TBI with hemorrhagic contusion in the right frontotemporal and left tempooccipital regions, with scattered subarachnoid hemorrhage, and a right occipitoparietal subdural. 

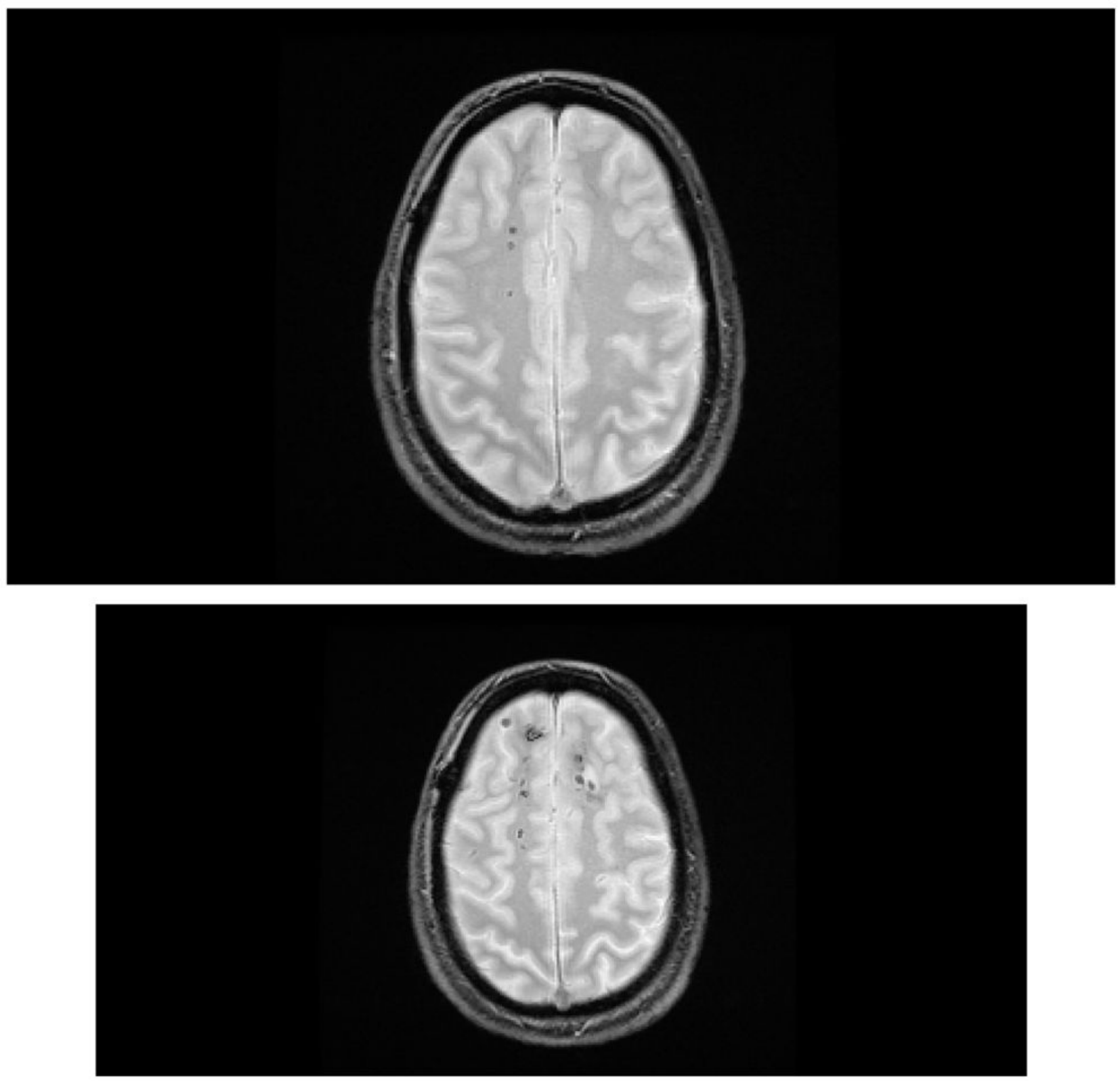

Figure 2.

Axial GRE MRI showing multiple punctate microhemorrhages consistent with diffuse axonal injury following a motor vehicle accident. 


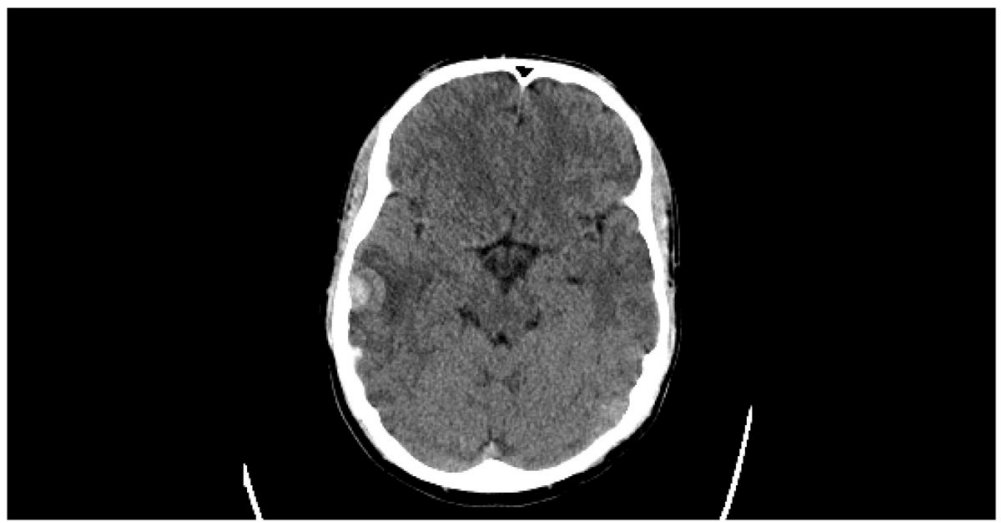

Figure 3.

Computed tomography showing a right temporal epidural hematoma with adjacent contusion and vasogenic edema. 

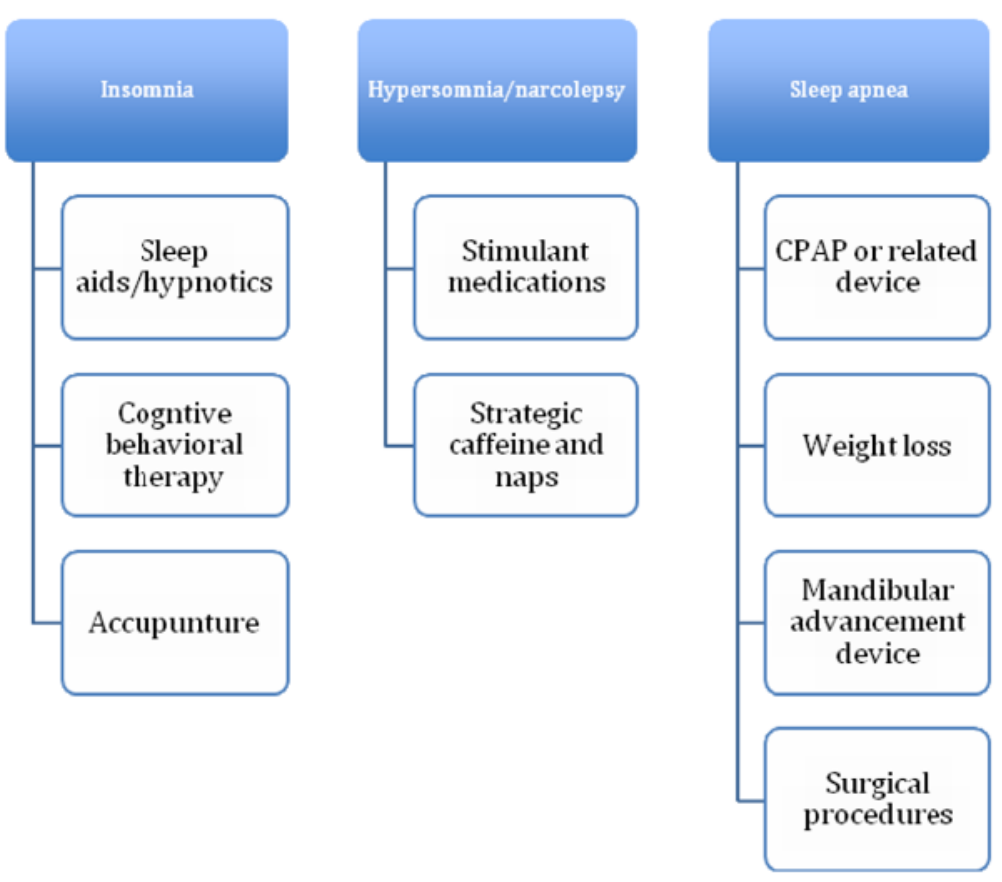

Flowchart 1.

Treatments Options 

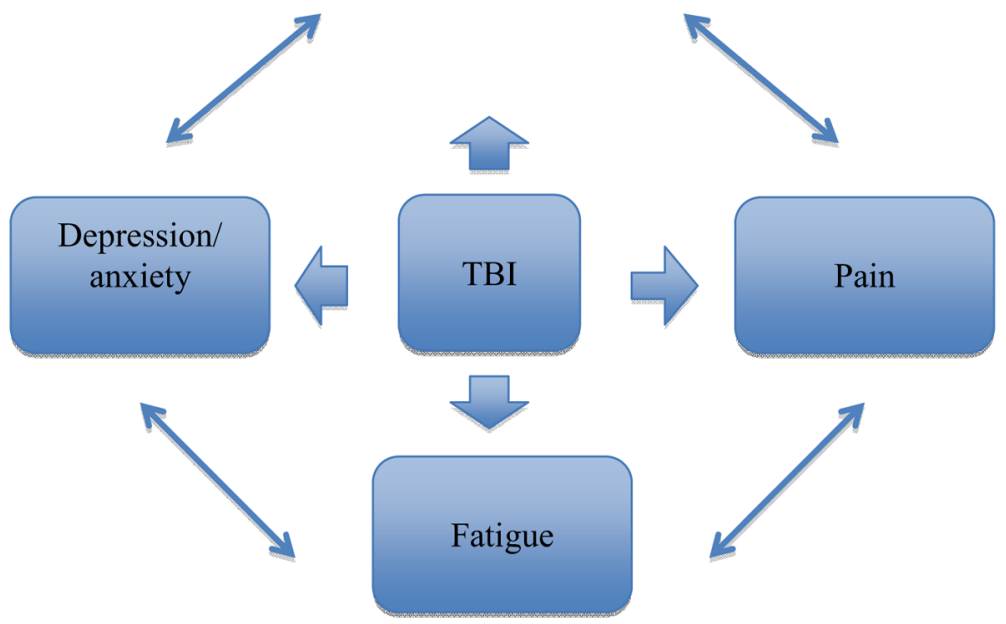

Flowchart 2.

Relationship of Sleep-Related Issues 


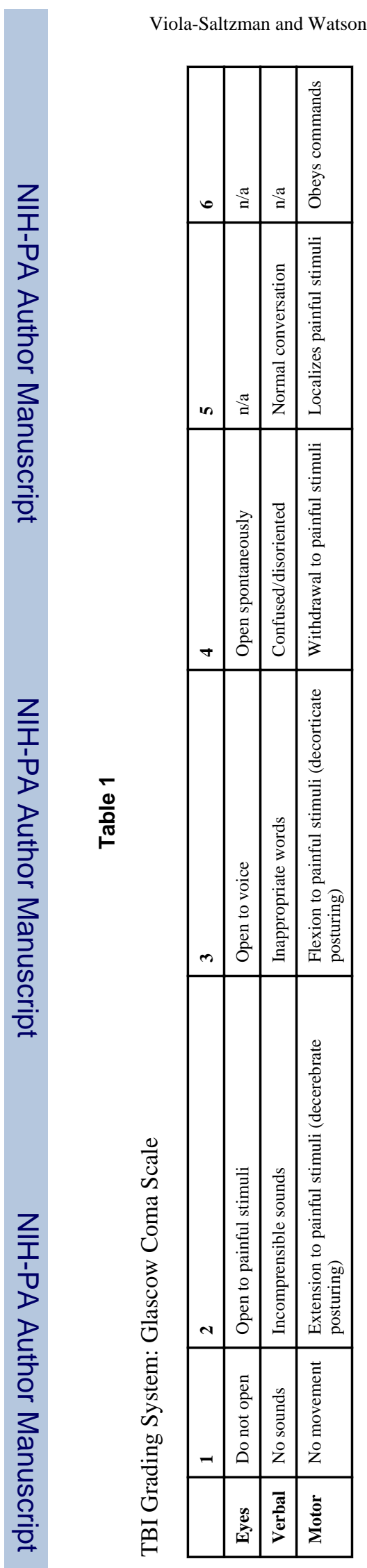

Page 19 
Table 2

Concussion Grading System: American Academy of Neurology

\begin{tabular}{|l|l|l|l|l|}
\hline & Confusion? & Loss of consciousness? & When to return to activity? & Previous same grade concussion? \\
\hline Grade 1 & $<15$ minutes & No & After 15 min if normal neurologic exam & Out of play for 1 week \\
\hline Grade 2 & $>15$ minutes & No & Out of play for 1 week & Out of play for 2 weeks \\
\hline Grade 3 & Yes & Yes & $\begin{array}{l}\text { Out of play for 1 week if LOC lasted only } \\
\text { "seconds" or out of play for 2 weeks if LOC } \\
\text { lasted "minutes" }\end{array}$ & Out of play for 1 month or more \\
\hline
\end{tabular}

